\title{
Citrate-mediated hydrometallurgical lead extraction and integrated electrochemical recovery from zinc leaching residue
}

Authors:

Karel Folens, Adam J. Williamson, Kylian Van Damme, Pieter Ostermeyer, Cristina García Timermans, Gijs Du Laing, Nico Boon, Tom Hennebel

Content:

Figure S1 : Powder XRD diffractogram

Pages:

$\mathrm{S} 1-\mathrm{S} 2$ 


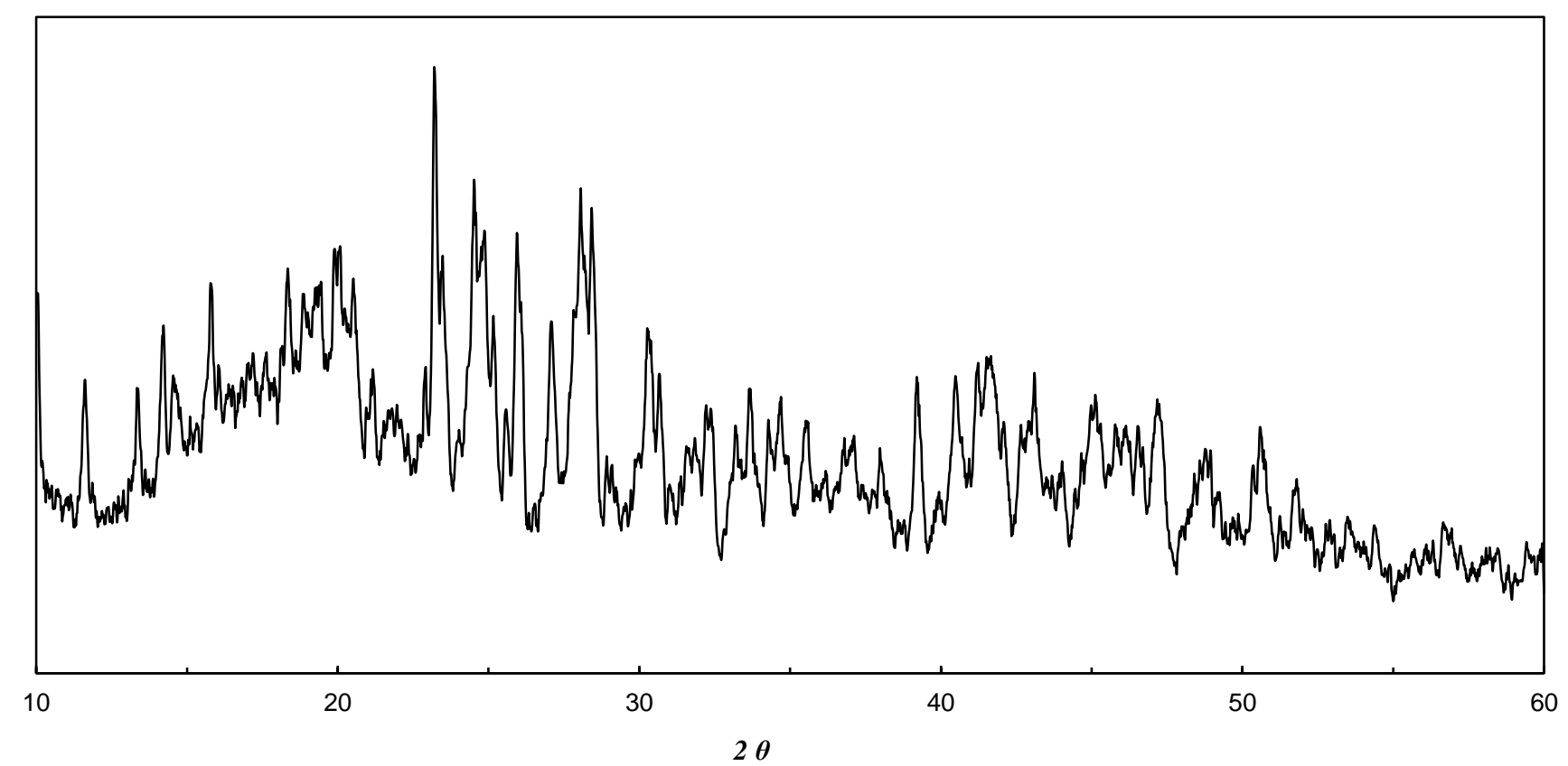

Figure S1. Powder X-ray diffraction (XRD) diffractogram of the white precipitate formed in the anode compartment recorded on a ThermoScientific ARL X'TRA Powder Diffractometer operating at $40 \mathrm{kV}$ and $40 \mathrm{~mA}$ using Cu $\mathrm{K}_{\alpha}$ radiation of wavelength $1.5406 \AA$. Structural identification indicates for an amorphous phase of $\mathrm{Pb}$. 